\title{
KIT Expression in Angiosarcomas and Fetal Endothelial Cells: Lack of Mutations of Exon 11 and Exon 17 of C-kit
}

\author{
Markku Miettinen, M.D., Maarit Sarlomo-Rikala, M.D., Jerzy Lasota, M.D. \\ Department of Soft Tissue Pathology, Armed Forces Institute of Pathology (MM, JL), Washington, D.C., \\ and Department of Pathology, Haartman Institute of the University of Helsinki (MS-R), Helsinki, Finland
}

C-kit proto-oncogene product (KIT, CD117) is a tyrosine kinase growth factor receptor for stem cell factor. This receptor is important for the development and maintenance of hematopoietic stem cells, mast cells, germ cells, melanocytes, and interstitial cells of Cajal and is constitutively expressed in them. Among mesenchymal tumors, KIT seems to be specific for the gastrointestinal stromal tumors, which consistently express this protein. Activating mutations in the tyrosine kinase or juxtamembrane domains of c-kit gene have been found in mastocytoma, seminoma, and gastrointestinal stromal tumors. Following up our initial observation of KIT expression in one angiosarcoma, we examined $\mathbf{5 0}$ angiosarcomas, 13 Kaposi sarcomas, 10 epithelioid hemangioendotheliomas, and 31 hemangiomas of different types for KIT expression using a polyclonal antiserum specific to KIT. Adult and fetal tissues and neovascular endothelia in $\mathbf{2 0}$ carcinomas were studied for comparison. More than half $(56 \%)$ of the angiosarcomas representing different clinicopathologic and histologic subtypes and 2 of 13 Kaposi sarcoma were KIT positive. All epithelioid hemangioendotheliomas and hemangiomas were negative, with the exception of two infantile hemangiomas that showed KIT reactivity. The fetal capillary endothelia of lungs, placenta, and soft tissues were also KIT positive, although in soft tissues and placenta, KIT positivity was more prominent in the first trimester. However, endothelia of adult vessels and neovascular capillaries of carcinomas were negative. None of the four KIT-positive angiosarcomas and one KIT-positive Kaposi sarcomas that were studied showed mutations in the juxtamembrane or tyrosine kinase domains of the c-kit gene. These

Copyright () 2000 by The United States and Canadian Academy of Pathology, Inc.

VOL. 13, NO. 5, P. 536, 2000 Printed in the U.S.A

Date of acceptance: November 22, 1999.

The opinions and assertions contained herein are the expressed views of the authors and are not to be construed as official or reflecting the views of the Departments of the Army or Defense.

Address reprint requests to: Markku Miettinen, M.D., Department of Soft Tissue Pathology, Armed Forces Institute of Pathology, 14th Street and

Alaska Avenue, N.W., Washington, DC 20306-6000; fax: 202-782-9182. results indicate that KIT expression occurs in a subset of angiosarcomas, and the expression probably represents oncofetal expression (i.e., reversion of the tumor cell phenotype to that of fetal endothelial cells that may show KIT expression).

KEY WORDS: Genetics, KIT, Vascular tumors. Mod Pathol 2000;13(5):536-541

C-kit gene encodes for a tyrosine kinase growth factor receptor for stem cell factor (also called mast cell growth factor). KIT protein (CD117 in the standardized terminology of leukocyte antigens) is constitutionally expressed in hematopoietic stem cells, mast cells, germ cells, melanocytes, certain basal epithelial cells, luminal epithelium of breast, and the interstitial cells of Cajal of the gastrointestinal tract. KIT protein is important for the development and maintenance of these cell types (1-6).

Among mesenchymal tumors, KIT is consistently expressed in the gastrointestinal stromal tumors (GISTs), the major subset of the mesenchymal tumors of the gastrointestinal tract, many of which also express another antigen of hematopoietic progenitor cells, CD34 (7-10). In a previous study, KIT was not found in other CD34-positive tumors, such as solitary fibrous tumor and Kaposi sarcoma (KS), and was only sporadically encountered in dermatofibrosarcoma protuberans and hemangiopericytoma (9).

Gain-of-function mutations in c-kit gene have been shown in mastocytosis (11-13), GIST (7, 1418 ), and more recently in seminoma (19). In mastocytosis and seminoma, different point mutations have been found in the tyrosine kinase domain (exon 17) at the same nucleotide (2467) position. In GISTs, the mutations involved the juxtamembrane domain, exon 11 of the c-kit gene. Most common, the mutations in GISTs are in frame deletions of several codons or, less common, in point mutations and insertions $(7,14-18)$.

Following up our initial immunohistochemical observation of KIT expression in one angiosarcoma, we analyzed 104 vascular tumors and fetal and 
adult endothelial cells for KIT expression. Some fetal blood vessels and more than half of the angiosarcomas showed KIT expression, but normal adult endothelia were negative. However, no mutations were found in exon 11 and exon 17 of c-kit gene. Therefore, KIT expression in angiosarcoma probably represents an oncofetal expression paralleling the KIT expression of developing endothelia.

\section{MATERIALS AND METHODS}

\section{Tissues}

KIT expression was studied in 50 angiosarcomas, $13 \mathrm{KS}, 10$ epithelioid hemangioendotheliomas, and 31 hemangiomas, including 6 infantile capillary hemangiomas obtained from the Soft Tissue Registry from the Armed Forces Institute of Pathology. The diagnosis of angiosarcoma was based on distinctive vasoformation by the tumor cells or by demonstration of CD31 in all cases included in this study. Histologically normal fetal tissues from first $(n=4)$, second $(n=7)$, and third trimesters $(n=3)$ were studied for comparison. In addition, KIT expression was studied in normal adult tissues from brain, skin, breast, subcutaneous soft tissues, skeletal muscle, tonsil, trachea, lung, liver, appendix, small intestine, colon, kidney, endometrium, myometrium, fallopian tube, and ovary. Twenty KITnegative carcinomas with tumor neovascularization were also studied, including 5 renal carcinomas, 5 ovarian high-grade carcinomas, 5 colonic adenocarcinomas, and 5 Merkel cell carcinomas.

\section{Immunohistochemistry}

The normal tissues, carcinomas, and vascular tumors were immunohistochemically evaluated for the KIT protein. A polyclonal antibody was used (sc-168; Santa Cruz Biotechnology, Santa Cruz, CA; diluted at 1:400). In control tissues, this antibody reproduced the known patterns of KIT specificity with expression in ovocytes, fetal testicular germ cells, mast cells, terminal ductal epithelia of breast, melanocytes, and Cajal cells of the gastrointestinal tract. The immunohistochemical studies were performed by the avidin-biotin complex method (Vectastain Elite; Vector Labs, Burlingame, CA) or by Ventana automated immunostainer (Ventana Medical Systems, Tucson, AZ, with their detection systems); equal results were documented in control stains. Diaminobenzidine added with hydrogen peroxide was used as the chromogen. Appropriate negative controls (omission of primary antibody) and positive controls (a multitissue block with 33 normal tissues) were evaluated in each run.

\section{Molecular Studies of c-kit Gene}

DNA for the polymerase chain reaction (PCR) amplification was obtained from formalin-fixed and paraffin-embedded tissues, and the quality of DNA templates was verified by amplification of two fragments of genomic DNA (133 bp and $268 \mathrm{bp}$ ) as previously reported (16). The entire exon 11 of c-kit gene was PCR amplified for 40 cycles with forward primer CK10.4 (16) and the reverse primer CK11.3 (5'-AGC CCC TGT TTC ATA CTG AC-3'). The PCR assay yielded amplification products of $250 \mathrm{bp}$. In one case with unoptimally preserved DNA, a seminested PCR was performed to amplify exon 11 of c-kit. Aliquot of the PCR products $(0.1 \mu \mathrm{l})$ from the CK10.4/CK11.3 reaction was reamplified (30 cycles) using forward CK10.4 and reverse CK11.2 primers (16). The semi-nested PCR assay yielded amplification products of $192 \mathrm{bp}$. The annealing temperature was $56^{\circ} \mathrm{C}$ for both assays. The region of exon 17 of c-kit with previously reported mutation at the position 2467 was PCR amplified for 30 cycles using forward primer CK17.1 (5' -TCC TTA CTC ATG GTC GGA TC-3') and reverse primer CK17.2 (5'-CAG GAC TGT CAA GCA GAG AA-3'). The annealing temperature was $50^{\circ} \mathrm{C}$. The PCR reaction conditions in all assays were the standard ones recommended by Perkin Elmer (Norwalk, CT). The PCR products were size-fractionated on $2 \%$ and $3.5 \%$ agarose gels, purified from the gels (Qiagene, Inc., Chatsworth, CA) and sequenced directly on a 373 DNA sequencer (Applied Biosystems, Foster City, CA). Computer analysis of the DNA sequences were performed using Lasergene software (DNASTAR, Madison, WI) in connection with the data of the GeneBank 110/EMBL57 database. To prevent PCR contamination, standard precautions were undertaken, including multiple negative controls in each experiment to monitor the possible contamination.

\section{RESULTS}

KIT (CD117) Expression in Embryonic But Not in Adult and Neovascular Endothelial Cells

A 6- to 7-week embryo showed KIT reactivity in capillaries of the placental villi (Fig. 1A) and the primitive mesenchyme (Fig. 1B). Villous trophoblast also showed KIT positivity that was weaker than that seen in the endothelial cells (Fig. 1A). KIT-positive capillary endothelia were also seen in the endocardium and the chorioallantoic sac of the 6 - to 7-week embryo. The capillary endothelial cells, along with scattered hematopoietic cells and portions of the developing spinal cord, were the only KIT-positive cells identified in the early embryo. Three other first trimester embryos/fetuses also showed KIT positivity in some but not all capillaries of soft tissues. Alveolar capillaries of lungs 

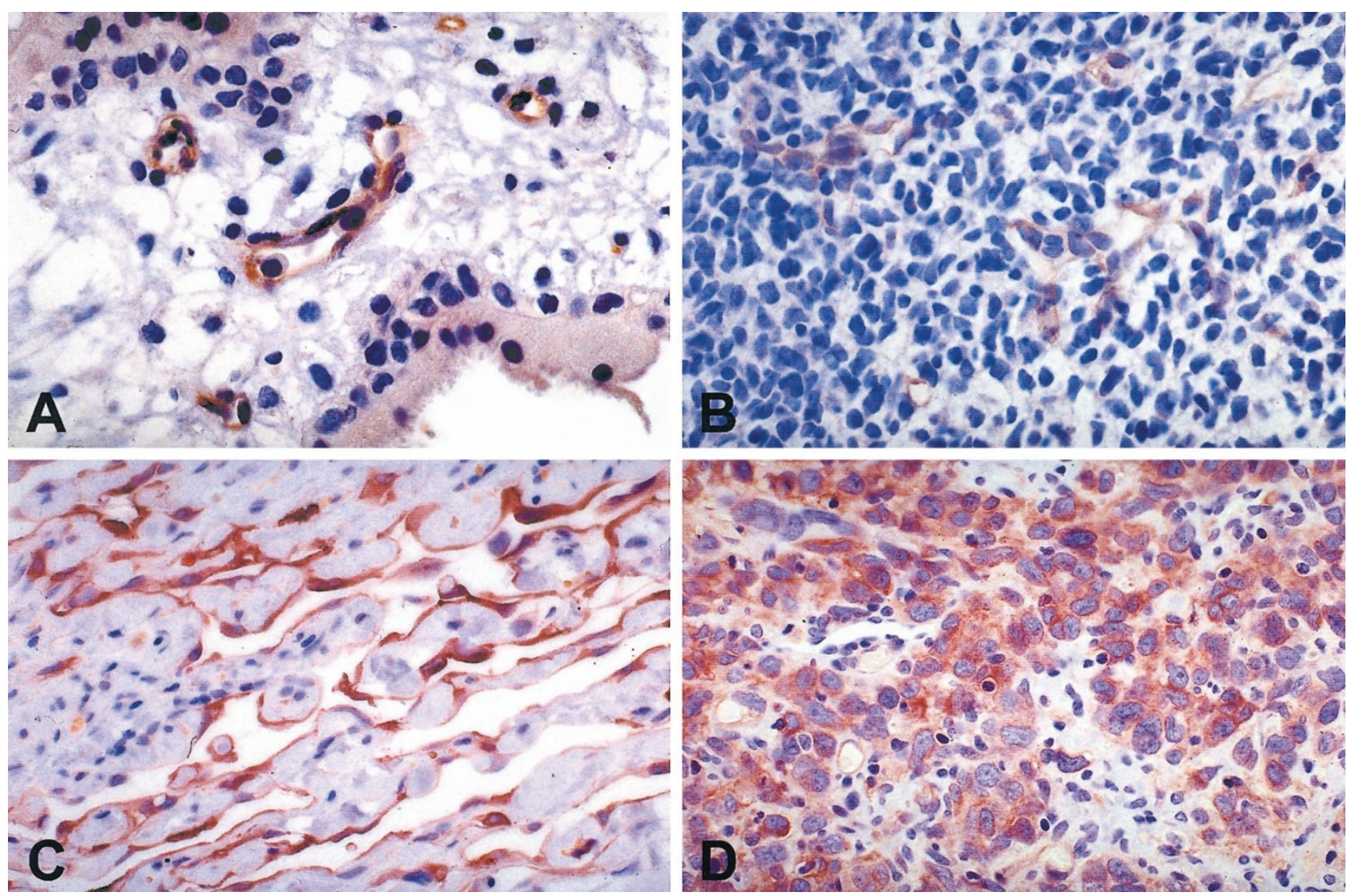

FIGURE 1. KIT expression in fetal endothelial cells and angiosarcomas (A, B, and C, immunoperoxidase, 480×). A, the capillary endothelial cells of the placental villi of a 6- to 7-week embryo are KIT positive. Note also KIT positivity of the trophoblast. B, the primitive mesenchyme of a 6- to 7week embryo shows delicate KIT-positive capillaries. C, the vasoformative structures of well-differentiated cutaneous angiosarcoma are KIT positive. D, the solid sheets of poorly differentiated tumor cells of a cutaneous angiosarcoma are KIT positive. Note two primitive lumen formations at lower left, one of them containing an erythrocyte.

were strongly positive. The KIT positivity also appeared in pulmonary alveolar capillaries of all seven second-trimester and all three third-trimester fetuses. Placental villi and soft tissues available of three second- and three third-trimester fetuses also showed KIT-positive vascular endothelia, although the number of positive cells was smaller in the third-trimester fetuses.

Vascular endothelial cells in adult tissues including soft tissues, tonsil, lung, intestines, and genitourinary tract were negative for KIT. Occasional intraluminal amorphous staining was observed, suggesting the presence of circulating soluble KIT; mast cells were consistently positive. Neovascularization as studied in 20 carcinomas (including 5 renal, 5 colonic, 5 ovarian, and 5 Merkel cell carcinomas) were negative for KIT. Positive mast cells were seen in all tumor specimens, and Cajal cells were seen in the intestines, which served as internal positive controls.

\section{KIT (CD117) Expression in Vascular Tumors}

Slightly more than half (28 of 50 [56\%]) of the angiosarcomas showed KIT positivity in the neo- plastic endothelial cells. Global reactivity in more than $50 \%$ of tumor cells was seen in 14 cases $(28 \%)$ (Table 1). The positive angiosarcomas included a representative cross-section of all types of angiosarcomas. Eleven of them were from the skin of scalp from elderly patients (67 to 80 years old), 3 were from the spleen, 2 were postirradiation angiosarcomas of the skin of breast from women, 1 was a postmastectomy angiosarcoma of arm, and the others were from miscellaneous soft tissue sites. Of the epithelioid angiosarcomas, four of seven showed KIT reactivity. The positive tumors included welldifferentiated cutaneous angiosarcomas with extensive vasoformation (Fig. 1C) and poorly differentiated angiosarcomas with rudimentary vasoformation and predominant solid growth pattern (Fig. 1D). Two of 13 KS were also KIT positive.

Benign hemangiomas of different types (capillary, cavernous, venous) were negative for KIT (Table 1), except for two infantile hemangiomas that showed focal (one case) or weak and more widespread KIT reactivity (one case) in the capillary endothelial cells. Epithelioid hemangioendotheliomas were consistently negative for KIT. In each 


\begin{tabular}{|c|c|c|}
\hline Tumor Category & $\begin{array}{l}\text { Positive/Total } \\
\text { (\%) }\end{array}$ & Comment \\
\hline AS, all & $28 / 50(56)$ & \\
\hline AS of scalp & $11 / 16$ (69) & $\begin{array}{l}3 \text { cases with }>50 \% \text { of tumor cells positive, } 6 \text { cases with } 10-50 \% \text { of tumor cells positive, } \\
2 \text { cases with }<10 \% \text { of tumor cells positive }\end{array}$ \\
\hline AS of deep soft tissues, nonepithelioid & $8 / 19(42)$ & 6 cases with $>50 \%$ of tumor cells positive, 2 cases with $30 \%$ of tumor cells positive \\
\hline AS of deep soft tissues, epithelioid & $3 / 7 \quad(43)$ & $20 \%, 20 \%$, and $80 \%$ of tumor cells positive \\
\hline Postirradiation AS of skin & $2 / 2 \quad(100)$ & Both cases with $>50 \%$ of tumor cells positive \\
\hline Postmastectomy AS, arm & $1 / 4 \quad(25)$ & $60 \%$ of tumor cells positive \\
\hline AS of spleen & $3 / 4 \quad(75)$ & $5 \%, 30 \%$, and $70 \%$ of tumor cells positive \\
\hline Kaposi sarcoma & $2 / 13(15)$ & $60 \%$ and $10 \%$ of tumor cells positive, respectively \\
\hline Epithelioid hemangioendothelioma & $0 / 10(0)$ & \\
\hline Capillary hemangioma, adult & $0 / 10(0)$ & \\
\hline Capillary hemangioma, infantile & $2 / 6 \quad(33)$ & 1 case with focal, 1 case with global but weak positivity \\
\hline Cavernous hemangioma & $0 / 5 \quad(0)$ & \\
\hline Venous hemangioma & $0 / 10(0)$ & \\
\hline
\end{tabular}

AS, angiosarcoma.

case, positive mast cells served as an internal control.

\section{Lack of c-kit Gene Mutations in Exons 11 and 17 in Angiosarcomas}

Four KIT-positive angiosarcomas and one KITpositive KS were evaluated by PCR amplification and direct sequencing for the mutations in the juxtamembrane (exon 11) and the catalytic, tyrosine kinase domain (exon 17). Only germline sequences were found in all five cases.

\section{DISCUSSION}

In this study, we have demonstrated immunohistochemically that more than half of angiosarcomas and a minority of KS express KIT (CD117), whereas this receptor is not immunohistochemically detectable in benign vascular tumors, with the exception of occasional infantile capillary hemangiomas. The KIT-positive angiosarcomas represented a crosssection of different clinicopathologic and histologic subtypes, including angiosarcomas in scalp, spleen, and arm in postmastectomy patients and those in postirradiation sites. Although it is desirable to confirm the immunohistochemical finding by Western blotting, this requires fresh tissue and is technically very difficult, as the ubiquitously present tissue mast cells inevitably contribute to the KIT protein content in the tissue extracts.

The lack of KIT expression in epithelioid hemangioendothelioma is notable; in contrast, three of seven epithelioid angiosarcomas were KIT positive. This difference may suggest that KIT expression more prominently appears in high-grade malignant endothelia representing a higher level of malignant transformation. Because of the inconsistent KIT expression in epithelioid angiosarcomas, this feature is not a reliable basis for the differential diagnosis between these two entities.
The KIT expression in half of the angiosarcomas should be considered in the immunohistochemical differential diagnosis of human tumors. Specifically, the KIT-positive intra-abdominal angiosarcomas should not be confused with gastrointestinal stromal tumors, especially because both tumor types commonly express CD34. Immunohistochemically, CD31 is a discriminatory marker, as this antigen is not expressed in GISTs, based on a previous study on more than 100 GISTs (20).

We also documented KIT expression in fetal but not in adult endothelia. KIT positivity was consistently documented in the alveolar capillaries of the lung of all fetuses and in the placenta and soft tissues preferentially in the early embryos/fetuses, but endothelial KIT positivity could not be found in alveolar capillaries of adult lung, soft tissues, or a variety of internal organs. The KIT expression in malignant vascular tumors, similar to some fetal endothelial cells, suggests that KIT expression in malignant vascular tumors represents oncofetal expression (i.e., reversal of the tumor cells to fetal phenotype). Its genetic mechanism remains to be elucidated.

Our results on KIT negativity of adult endothelia agree with a previous study that was based on frozen and acetone-fixed tissue; this study specifically stated KIT negativity of arteries, veins, and capillaries (21). Another study stated negativity of cells and tissues other than mast cells, germ cells, and some epithelia without a specific mention on endothelia (5). One survey stated KIT staining of "isolated small size vessels" and "capillary walls" without a specific mention on endothelia (22). Weak KIT expression in endothelial cells was noted in a recent study; the ages of subjects or sites of observation were not mentioned (23). KIT expression, however, has been noted in murine embryonic endothelial cells, specifically in the hematopoietic tissues (24, 25). In human tissue, c-kit mRNA has been local- 
ized in umbilical vein endothelia, placental endothelia, and villous trophoblast $(26,27)$ by reverse transcription-PCR; in this study, we also observed KIT positivity in early trophoblast.

The results suggest that if KIT expression occurs in adult endothelia, then it is beyond the limits of immunohistochemical detection. Delineation of the role of KIT in fetal endothelia requires functional studies beyond the scope of this investigation.

Among tumors expressing KIT, gain-of-function mutations have been found in mastocytosis (11-13) and seminomas (19) in the catalytic, tyrosine kinase domain and in GISTs in the regulatory, juxtamembrane domain $(7,14-18)$. Our results indicate that KIT expression in angiosarcoma is not at least commonly associated with the presence of such activating c-kit mutations, as only germline was found upon sequencing of exons 11 and 17 of c-kit in five tumors. Recently, adenoid cystic carcinomas were also found to express KIT, but these tumors were negative for c-kit mutations in exons 11 and 17 (28).

In summary, the common expression of KIT immunoreactivity in angiosarcoma parallels the KIT expression seen in fetal capillary endothelial cells and suggests that KIT expression in angiosarcoma may represent oncofetal expression (i.e., reversal of the tumor cells to the fetal phenotype). Also, the potential KIT positivity of angiosarcomas has to be considered in the immunohistochemical differential diagnosis of tumors.

\section{REFERENCES}

1. Yarden Y, Kuang WS, Yang-Fend T, Coussens L, Munemitsas S, Dull TJ. Human proto-oncogene kit, a new cell surfacereceptor tyrosine kinase for an unidentified ligand. EMBO J 1987;6:3341-51.

2. Williams DE, Eisenman J, Baird A, Rauch C, van Ness K, March CJ, et al. Identification of a ligand for the c-kit protooncogene. Cell 1990;63:167-74.

3. Zsebo KM, Williams DA, Geissler EN, Broudy WL, Martin FH, Atkins HL, et al. Stem cell factor is encoded at the SI locus of the mouse and is ligand for the c-kit tyrosine kinase receptor. Cell 1990;63:214-24.

4. Vliagoftis H, Worobec AS, Metcalfe DD. The proto-oncogene c-kit and c-kit ligand in human disease. J Allergy Clin Immunol 1997;100:435-40.

5. Tsuura Y, Hiraki H, Watanabe K, Igarashi S, Shimamura K, Fukuda T. Preferential localization of c-kit product in tissue mast cells, basal cells of skin, epithelial cells of breast, small cell lung carcinoma and seminoma/dysgerminoma in human: immunohistochemical study of formalin-fixed, paraffin-embedded tissues. Virchows Arch 1994;424:135-41.

6. Maeda H, Yamagata A, Nishikawa S, Yoshinaga K, Kobayshy S, Nishi K, et al. Requirement of c-kit for development of intestinal pacemaker system. Development 1992;116:369-75.

7. Hirota S, Isozaki K, Moriyama Y, Hashimoto K, Nishida T, Ishiguro S, et al. Gain-of-function mutations of c-kit in human gastrointestinal stromal tumors. Science 1998;279:57780 .
8. Kindblom LG, Remotti HE, Aldenborg F, Meis-Kindblom JM. Gastrointestinal pacemaker cell tumor (GIPACT). Gastrointestinal stromal tumors show phenotypic characteristics of the interstitial cells of Cajal. Am J Pathol 1998; 152:1259-69.

9. Sarlomo-Rikala M, Kovatich A, Barusevicius A, Miettinen M. CD117: a sensitive marker for gastrointestinal stromal tumors that is more specific than CD34. Mod Pathol 1998;11: 728-34.

10. Sircar K, Hewlett BR, Huizinga JD, Chorneyko K, Berezin I, Riddell RH. Interstitial cells of Cajal as precursors for gastrointestinal stromal tumors. Am J Surg Pathol 1999;23:37789.

11. Furitsu T, Tsujimura T, Tono T, Ikeda H, Kitayama H, Koshimizu U, et al. Identification of mutations in the coding sequence of the proto-oncogene c-kit in a human mast cell leukemia cell line causing ligand-independent activation of c-kit product. J Clin Invest 1993;92:1736-44.

12. Longley BJ, Tyrrell L, Lu SZ, Ma YS, Langley K, Ding TG, et al. Somatic c-KIT activating mutation in urticaria pigmentosa and aggressive mastocytosis: establishment of clonality in a human mast cell neoplasm. Nat Genet 1996;12:312-4.

13. Nagata H, Worobec AS, Oh CK, Chowdhury BA, Tannenbaum S, Suzuki Y, et al. Identification of a point mutation in the catalytic domain of the proto-oncogene c-kit in peripheral blood mononuclear cells of patients who have mastocytosis with an associated hematologic disorder. Proc Natl Acad Sci U S A 1995;92:10560-5.

14. Nakahara M, Isozaki K, Hirota S, Miyagawa J-I, Hase-Sawada $\mathrm{N}$, Taniguchi $\mathrm{M}$, et al. A novel gain-of-function mutation of c-kit gene in gastrointestinal stromal tumors. Gastroenterology 1998;115:1090-5.

15. Kitamura Y, Hirota S, Nishida T. Molecular pathology of c-kit proto-oncogen and development of gastrointestinal stromal tumors. Ann Chir Gynecol 1998;87:282-6.

16. Lasota J, Jasinski M, Sarlomo-Rikala M, Miettinen M. Mutations in exon 11 of c-kit occur preferentially in malignant versus benign gastrointestinal stromal tumors and do not occur in leiomyomas and leiomyosarcomas. Am J Pathol 1999;154:53-60.

17. Ernst SI, Hubbs AE, Przygodzki RM, Emory TS, Sobin LH, O'Leary TJ. KIT mutation portends poor prognosis in gastrointestinal stromal/smooth muscle tumors. Lab Invest 1998; 78:1633-6.

18. Moskaluk CR, Tian Q, Marshall CR, Rumpel CA, Franquemont DW, Frierson HF. Mutations of c-kit JM domain are found in a minority of human gastrointestinal stromal tumors. Oncogene 1999;18:1897-902.

19. Tian Q, Frierson HF, Kruystal GW, Moskaluk CR. Activating c-kit gene mutations in human germ cell tumors. Am J Pathol 1999;154:1643-7.

20. Miettinen M, Virolainen M, Sarlomo-Rikala M. Gastrointestinal stromal tumors-value of CD34 antigen in their identification and separation from true leiomyomas and schwannomas. Am J Surg Pathol 1995;19:207-16.

21. Lammie A, Drobnjak M, Gerald W, Saad A, Cote R, Cordon-Cardo C. Expression of c-kit and kit ligand proteins in normal human tissues. J Histochem Cytochem 1994;42:1417-25.

22. Natali PG, Nicotra MR, Nicotra R, Sures I, Santora E, Bigotti $\mathrm{E}$, et al. Expression of c-kit receptor in normal and transformed human nonlymphoid tissues. Cancer Res 1992;613943.

23. Arber DA, Tamayo R, Weiss LM. Paraffin section detection of the c-kit gene product (CD117) in human tissues: value in the diagnosis of mast cell disorders. Hum Pathol 1998;29: 498-504.

24. Yoshida H, Takakura N, Hirashima M, Kataoka H, Tsuchida $\mathrm{K}$, Nishikawa S. Hematopoietic tissues, as a playground of 
receptor tyrosine kinases of the PDGF-receptor family. Dev Comp Immunol 1998;22:321-32.

25. Bernex F, De Sepulveda P, Kress C, Elbaz C, Delouis C, Panthier JJ. Spatial and temporal patterns of c-kit expressing cells in WlacZ/ + and WlacZ/WlacZ mouse embryos. Development 1996;122:3023-33.

26. Yamaguchi H, Ishii E, Saito S, Tashiro K, Fujita I, Yoshidomi $\mathrm{S}$, et al. Umbilical vein endothelial cells are an important source of c-kit and stem cell factor which regulate the pro- liferation of hemopoietic progenitor cells. Br J Haematol 1996;94:606-11.

27. Doneda L, Bulfamante G, Grimoldi MG, Volpi L, Larizza L. Localization of fos, jun, kit and SCF mRNA in human placenta throughout gestation using in situ RT-PCR. Early Pregnancy 1997;3:265-71.

28. Holst VA, Marshall CE, Moskaluk CA, Frierson HF. KIT protein expression and analysis of c-kit gene mutation in adenoid cystic carcinoma. Mod Pathol 1999;12:956-60. 